\title{
Liaison psychiatry in detection and management of mental illness
}

\author{
Margaret Semple, David Brown and Elizabeth Invine
}

\begin{abstract}
Of 299 referrals to the Dundee general peychiatry liaison service over a six month period, deliberate self-harm (DSH) was the reason in $83 \%$. An overdose was used in $94 \%$, and alcohol misuse occurred in $56 \%$ of DSH episodes. Filfy-two per cent of refenals were followed up by the general psychiatiy service; $31 \%$ of these were admitted directty to a psychiatic ward, $10 \%$ on a compulsory basis. At follow-up, $23 \%$ remained in contact with the Dundee psychiattic service. Twentythree per cent of all patients referred to the Area Alcohol Service (AAS) were in contact with it six months later. Clearty, liaison psychiatry has a role in detection and management of significant mental disorder.
\end{abstract}

General psychiatry liaison services have seldom been studied, apparently because of inadequate record keeping which has made it impossible for either psychiatrists or managers to assess the numbers of people seen or the resources used (Mayou et al, 1990). Hall (1994) looked at reasons for and disposal of referrals to general psychiatry liaison services. To our knowledge, there are few short-term follow-up studies of such referrals.

Mayou et al (1994) followed up, over a 14-year period, a four-year cohort of consecutive inpatient referrals to a consultation-liaison service of a British general hospital, and revealed that a third made considerable use of a wide range of specialist psychiatric services.

\footnotetext{
Aims

First we surveyed the sources of all referrals, over a six-month period, to the Dundee general psychiatry liaison services. The DSH patients were of particular interest as they constituted the vast majority of the referrals.

Second, we monitored the management of the referrals. Specific note was taken of characteristics of patients followed up by the general psychiatry service and the Area Alcohol Service (AAS).

Lastly, we carried out a six-month follow-up on Dundee based patients and all patients referred to the AAS.
}

\section{The study}

All referrals made between 1 January 1993 and 30 June 1993 were studied. The Dundee general psychiatry liaison service routinely assesses referrals seven days per week. From Mondays to Fridays, all ward referrals are made by telephone to the senior medical secretary. The liaison consultant delegates appropriate referrals to junior medical staff and sees the remainder personally. Outwith normal working hours, the duty senior registrar sees all ward referrals. Direct referrals from the Accident \& Emergency department are seen by junior medical staff. Such referrals were rare and were not included in this survey.

Patients under 16 years and those still at school are assessed separately by the child and adolescent psychiatry service. Patients over 65 years are assessed by the psychiatry of old age service. A questionnaire devised by the authors was completed by the assessing psychiatrist after each referral. As well as general demographic data, information was sought on referral source, DSH or other liaison, method of DSH used and alcohol intake. The type of disposal and use of the Mental Health (Scotland) Act 1984 was noted. Six-month follow-up of patients was limited to those from the Dundee catchment area. By utilising the local psychiatric case notes, we detected most of those people currently in contact with the psychiatric services. However, a number of people may have been lost to follow-up by moving address. Similarly, patients referred to the AAS were followed up six months after their initial appointment date, to monitor if they were in current contact with the Service.

\section{Findings}

Two hundred and ninety-nine people were seen (143 males and 156 females); 239 (80\%) lived in the Dundee catchment area (population $180000)$. The rest were from neighbouring catchment areas. The mean age of the patients was 34.8 years (age range 16-65). 
Table 1. Laison survey grouped for age and deliberate self-harm

\begin{tabular}{lllll}
\hline Age & & Total & Males & Females \\
\hline $16-25$ & $n$ & 80 & 31 & 49 \\
& DSH & $74(92.5 \%)$ & $28(90 \%)$ & $46(94 \%)$ \\
& O/D & $71(89 \%)$ & $26(84 \%)$ & $45(92 \%)$ \\
$26-35$ & O/D as \% DSH & $(96 \%)$ & $(93 \%)$ & $(98 \%)$ \\
& $n$ & 85 & 46 & 39 \\
& DSH & $77(90.6 \%)$ & $43(93 \%)$ & $34(87 \%)$ \\
& O/D & $70(82 \%)$ & $40(87 \%)$ & $30(77 \%)$ \\
$36-45$ & O/D as \% DSH & $(91 \%)$ & $(93 \%)$ & $(88 \%)$ \\
& $n$ & 77 & 35 & 42 \\
& DSH & $63(81.8 \%)$ & $24(68 \%)$ & $39(93 \%)$ \\
& O/D & $61(79 \%)$ & $24(68 \%)$ & $37(88 \%)$ \\
$46-55$ & O/D as \% DSH & $(97 \%)$ & $(100 \%)$ & $(95 \%)$ \\
& $n$ & 40 & 19 & 21 \\
& DSH & $28(70 \%)$ & $13(68 \%)$ & $15(71 \%)$ \\
& O/D & $27(68 \%)$ & $12(63 \%)$ & $15(71 \%)$ \\
$56-65$ & O/D as \% DSH & $(96 \%)$ & $(92 \%)$ & $(100 \%)$ \\
& $n$ & 17 & 12 & 5 \\
& DSH & $9(52.9 \%)$ & $6(50 \%)$ & $3(60 \%)$ \\
& O/D & $8(47 \%)$ & $5(42 \%)$ & $3(60 \%)$ \\
& O/D as \% DSH & $(89 \%)$ & $(83 \%)$ & $(100 \%)$ \\
\hline
\end{tabular}

O/D, overdose

Two hundred and one $(67 \%)$ patients were referred by Ward 15. Ninewells Hospital, the acute medical admission ward for the Dundee area; the general medical wards of Ninewells Hospital referred a further $71(24 \%)$. There were few referrals from other sources $(n=27)$. These included general surgery, orthopaedic surgery, obstetrics, neurology and others.

Ward 15 had 3372 admissions over the period of the survey; $372(11 \%)$ were due to DSH. Thus DSH cases contribute significantly to medical admissions.

Most liaison referrals (251; 83\%) were deliberate self-harmers; 192 (76.5\%) of DSH cases were referred by Ward 15, Ninewells Hospital. The majority $(192 / 201 ; 95.5 \%)$ of the referrals from Ward 15 were cases of DSH; $51 / 71$ (72\%) of referrals made by the general medical wards were cases of DSH but only 51/251 (20\%) of all DSH cases came from this source. However, as patients were often rapidly transferred from Ward 15 to other medical wards, it is useful to combine the figures. Thus the vast majority (243/272; 89\%) of referrals from these wards are cases of DSH and almost all DSH cases $(243 / 251$; 97\%) came from these wards.

Among the DSH cases, 237 (94\%) had taken an overdose, seven (3\%) had self-injured and four (2\%) had done both. Two referrals had used other forms of DSH and in one case the DSH method was unknown. In the overdose/overdose and selfinjury group ( $n=241)$, analgesics were the drugs most frequently used ( $n=95 ; 39 \%)$. Others were antidepressants ( $n=33 ; 14 \%$ ) or benzodiazepines $(n=25 ; 10 \%)$. In 82 cases a mixture of drugs was utilised and in six cases unknown drugs were involved. Alcohol was involved in 141 (56\%) of all DSH attempts.

All referrals were sub-grouped by age bands and gender (Table 1). These sub-groups reveal greater numbers of males than females in the 2635 and 56-65 age bands for total liaison referrals, DSH and overdose sub-groups. The reverse is true for other age bands.

The management of the patients was also examined (Table 2). Within the in-patient group, 23 were considered suicidal. Three males and two females were detained under the Mental Health (Scotland) Act 1984 to enable treatment to be carried out.

A further 22 DSH patients were referred to the Tayside Alcohol Problems Service (TAPS). Three individuals were referred twice, so there were 25 referrals (17 males and 5 females). Prior to being offered an out-patient appointment, patients were asked to complete a questionnaire regarding alcohol-related issues. Twenty-one (95\%) returned the questionnaires and were offered an appointment at a TAPS out-patient clinic.

Table 2. Liaison survey management by Dundee psychiatric senice $(n=160)$

\begin{tabular}{llrc}
\hline & Total & Mate & Female \\
\hline In-patients & 49 & 21 & 28 \\
Day patients & 10 & 5 & 5 \\
Out-patients & 97 & 41 & 56 \\
CPN only & 4 & 1 & 3 \\
\hline
\end{tabular}

CPN, community psychiatric nurse 
Table 3. Liaison survey at six-month follow-up of Dundee based patients $(n=239)$

\begin{tabular}{lr}
\hline No contact" & $184(77 \%)$ \\
In-patient & $4(2 \%)$ \\
Day patient & $9(4 \%)$ \\
Out-patient & $39(16 \%)$ \\
CPN only & $1(1 \%)$ \\
Unspecified & $2(1 \%)$ \\
\hline
\end{tabular}

CPN, community psychiatric nurse

"There has been one death, not by sulcide

Dr Peter Rice, Consultant Psychiatrist with TAPS, has indicated that the response rates to the questionnaires is about $70 \%$ so this group had a higher response rate than average. Subsequently, $16(76 \%)$ of these people attended the TAPS clinic.

A six-month follow-up of Dundee-based patients ( $n=239$ ) was carried out by examining the Dundee psychiatric case notes (Table 3).

At six-month follow-up of patients given a first appointment by TAPS, 5 (23\%) were still in contact with the service. The remainder had been discharged or had defaulted.

\section{Comment}

Referrals

As in other UK studies, the majority of referrals to the Dundee general psychiatry liaison service were parasuicides. It is not routine policy in Dundee to refer all adult DSH cases to the general psychiatry liaison service. Personal communication indicates that the referral rate is approxdmately $80 \%$. Informal communication with other hospital specialists indicates general satisfaction with the psychiatry liaison service.

The excess of female referrals repeats findings of previous studies in the UK. However, the excess of male DSH cases in the 26-35 age groups may reflect the increasing suicide rates in young men (Crombie, 1990). As in previous Scottish studies, associated alcohol consumption is present in a high percentage of cases of DSH.

\section{Management}

After the initial assessment, the patient's management was transferred to the General Service. Although the Dundee general psychiatry service does not operate a local sectorised system, if possible, patients were transferred to available beds in the Ninewells Psychiatric Unit.

Females were more likely to be offered follow-up by the general psychiatry service. In contrast, males were more likely than females to be referred to AAS. This finding has been reported elsewhere (Hall, 1994).
A sixth of all referrals were admitted directly to a psychiatric ward. The majority were admitted on a voluntary basis but $10 \%$ refused treatment and had to be detained under the Mental Health (Scotland) Act 1984. This emphasises the importance of immediate bed availability for crisis intervention.

\section{Follow-up}

A quarter of liaison referrals remained in contact with the service. Females were more likely than males to be in treatment. TAPS also continued to have contact with a quarter of patients who had been given an appointment with the service. More males than females remained in contact.

\section{Conclusions}

This survey was concerned with referrals from other clinical specialities. The high percentage of referrals for DSH confirms the findings of another Scottish survey (Hall, 1994). There were only 48 referrals which were non-DSH. If the referrals from the general medical wards were excluded. there were few referrals $(n=27)$ from other sources. However, if the liaison service were to expand referrals might increase, particularly if more active links were established with other specialities.

Other follow-up studies of DSH (O'Brien, 1987) have also illustrated a high non-attendance rate at out-patient clinics. The low numbers of patients recetving day hospital follow-up was because this study was carried out shortly before the opening of a new resource centre in Dundee. Since then, the number of patients receiving day hospital follow-up has increased. This seems to be an appropriate use of resources, particularly if it improves follow-up of patients by assertive outreach. It may also reduce the number of patients requiring in-patient treatment. For audit purposes, the impact of increasing the community resources could be monitored by repetition of this study.

\section{Acknowledgements}

We would like to thank Dr Barbara Ballinger, Dr Tony Pelosi and Dr Peter Rice for their helpful comments on the text.

\section{References}

Crombie, I. K. (1990) Suicide in England and Wales and in Scotland. An examination of divergent trends. Brttish Journal of Psychiatry. 167, 529-532. 
HALL, D. J. (1994) A psychiatric liaison service in a general hospital. Referrals and their appropriateness. Scottish Medical Journal, 39, 141-144.

Mayou, R. Anderson, H., Fetnmann, C., et al (1990) The present state of consultation and Haison psychlatry. Psychiatric Bulletin, 14, 321-325.

-. SIMPKIN, S. \& COBB, A. (1994) Use of psychiatric services by patients referred to a consultation unit. General Hospital Psychiatry, 16. 354-357.

O'Brien, G. O., Holton, A. R. HURREN, K., et al (1987) Deliberate self harm and prediction of outpatient attendance. Britsh Joumal of Psychiatry. 150. 246-247.
"Margaret Semple, formerly Senior Registrar in Psychiatry, Royal Dundee Liff Hospital, Liff by Dundee, DD2 5NF; David Brown, Consultant Psychiatrist, Gartnavel Royal Hospital, Glasgow G12 OYN; and Elizabeth Irvine, Audit Facllitator. Royal Dundee Liff Hospital, Liff by Dundee DD2 5NF

*Correspondence: Margaret Semple, Consultant Psychiatrist, Hairmyres Hospital, East Kilbride G75 8RG

\title{
GASKELL ACADEMIC SERIES
}

\section{Interpersonal Factors in Origin and Course of Affective Disorders}

\author{
Edited by $\mathrm{Ch}$. Mundt, with the assistance of Hugh Freeman
}

This detailed overview of the latest research on affective disorders brings together authors of international background and repute. Both a theoretical and practical approach to the origin and course of affective disorders is presented, covering specific problems and settings. The principal areas covered are: personality factors, risk and course; social support; marital and family interaction; and intervention.

- $£ 30.00 \bullet 396 p p . \bullet 1995 \bullet$ ISBN 1902241907

Available from bookshops and from the Publications Department, Royal College of Psychiatrists, 17 Belgrave Square, London SW1X 8PG (Tel. 0171-235 2351, extension 146) 